\title{
Preliminary Investigation of Micro-V-Bending
}

\author{
Gandjar Kiswanto ${ }^{1}$, Aida Mahmudah ${ }^{1}$ and Dedi Priadi ${ }^{2}$ \\ ${ }^{1}$ Mechanical Engineering Department, Universitas Indonesia, Indonesia \\ ${ }^{2}$ Metallurgy and Material Engineering Department, Universitas Indonesia, Indonesia
}

\begin{abstract}
Bending in sheet metal forming is defined as uniformly straining process around a linear axis. A V-bending process is normally used in sheet metal working due to the tool and process simplicity. The main problem in bending process is a springback occurrence which causes an error in part dimension. In a micro level, the springback angle is difficult to be assessed because of the influence of size effects in all aspects of the system. The springback behavior has been investigated in many previous kinds of research. However, the springback correction is still needed to be studied extensively so that it can be implemented reliably in micro-bending. The purpose of this research is to investigate the influence of punch velocity and holding time to the springback angle. The process is performed to the $0.1 \mathrm{~mm}$ thickness of copper foil. The punch velocities are $0.1 \mathrm{~mm} / \mathrm{s}, 1 \mathrm{~mm} / \mathrm{s}$, and $10 \mathrm{~mm} / \mathrm{s}$. While the variation of holding time, which is set during the bottoming stage, are $7 \mathrm{~s}, 9 \mathrm{~s}$, and $11 \mathrm{~s}$. The result shows that the punch velocity clearly influences the springback angle. In addition, the holding time during the bottoming stage is a potential factor in springback angle correction.
\end{abstract}

\section{Introduction}

With the increasing of micro-parts demand due to the trend towards miniaturization, many kinds of research have been encouraged to conduct a development of a micro-manufacturing system and investigate the process at the micro level. One of the favorite methods for producing a micro-part is micro sheet metal forming. Bending is a basic configuration forming process in producing 3D profiles of micro-parts such as microelectric contacts/switches, mechanical sensors and 3D sheet metal profile for optical devices housing.

Bending in sheet metal forming is defined as a straining process of metal around a straight axis [1]. During bending, the top section of material may be stretched while the bottom section is compressed. The most widely used in bending process are U-bending and V-bending.

The main issue in bending process is springback phenomenon that occurs when the foil is unloaded. Springback is an elastic recovery in plastic deformation that causes deviation from the desired dimension so that it reduces the quality of bent-part and generate assembly difficulties.

The springback amount in micro bending is influenced by the $t / d$ ratio. When the thickness of the material is less than $350 \mu \mathrm{m}$, the springback angle increase with a decrease of $\mathrm{t} / \mathrm{d}$ ratio [2]. Diehl et al. [3] found that springback behavior of SE-CU 58 was different for the thickness less than $100 \mu \mathrm{m}$ and larger than $100 \mu \mathrm{m}$. This result caused by the different dominant factor that influences the amount of springback angle.
The grain properties also affect the springback behavior in micro level. Liu et al. [4] found that a large springback occurs with thickness decreasing or grain size increasing. Besides, an increasing of elastic anisotropy of surface grains with the reduction of grains along the thickness direction will cause the springback angle scattering [4, 5]. Chen et al. [6] discovered that yield strength and maximum punch force decrease with a decrease of $t / d$ ratio. It was also found that when the $t / d$ ratio is smaller than 2, spring-forward occurs.

Other researchers explained that deformation behavior in micro bending is mostly affected by plastic strain gradient hardening that requires the characteristic length, $l$, which is depended on the shear modulus, the yield strength and the Burgers vector of the material $[7,8]$.

The plastic deformation causes the increasing of material hardness which the highest value was indicated near the neutral axis $[9,10]$. The grain properties distribution in the forming area induces a significant influence on the springback behavior. Thus, Fang et al. [11] considered the grain heterogeneity in On tessellation application to predict the springback during micro $\mathrm{V}$ bending in finite element model.

It is necessary to control springback angle in obtaining a good part quality and facilitating the next micro-part assembly process. Zhen-Yuan [12] decreased the bending moment in bending area with a coining process so that and springback angle would be decreased. Besides, Ma et.al [5] stated that in a roll bending test, the springback angle, and its scattering can be reduced by controlling the sizing repetitions, sizing force, holding time and punch speed. 
Furthermore, Zheng et al. [13] investigated an elevated temperature bending process with thin pure titanium foils. Since the flow stress of surface became lower than in room temperature, the springback angle decrease with decreasing foil thickness.

The previous controlling springback studies need an additional implementation to reduce the springback angle. Consequently, the properties of the micro-bent part may be changed. In this study, a preliminary investigation is held to observe the springback controlling by applying a higher punch velocity and holding time in a micro-Vbending process. A copper foil with $1 \mathrm{~mm}$ thickness is preferred as a material specimen.

\section{Micro-V-bending}

As well as in macro range, several basic techniques in a micro-bending process can be used to make a bent-shape. Because of the simplicity and the wider application in bending angle, $\mathrm{V}$-bending is a popular method. Two common ways in $\mathrm{V}$-bending are air-bending and coinbending [14], as shown in Figure 1 and 2, respectively. In air-bending, the punch should always be in V-shaped, while the die may in $\mathrm{U}$ or $\mathrm{V}$ shaped (figure $1 \mathrm{a}$ and $1 \mathrm{~b}$ ). In the other hand, the punch and die should always be in Vshaped for coin-bending (Figure 2). With an air-bending application, various bending angles can be obtained with a single V-bending tool by controlling the length of punch trajectory.

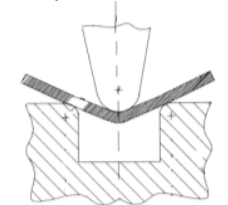

a)

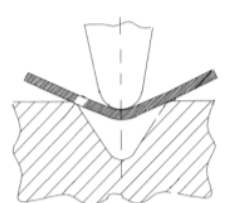

b)
Figure 1. Air-bending a) U-shaped die and; b) V-shaped die [14]

The coin-process in V-bending has four distinct stages to complete a bending process (Figure 2). The first stage is free-bending (Figure 2a). In the second stage, the end of the workpiece is touching the side walls of the die (Figure 2b). While, the end of the workpiece is touching the side walls of the punch in the third stage (Figure 2c). Finally, the fourth stage is a bottoming stage which all surfaces of the workpiece are touching the punch and the die (Figure $2 \mathrm{~d}$ ). In this stage, the bending process is completed.

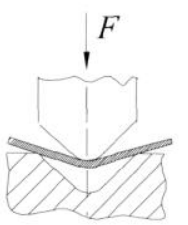

a)

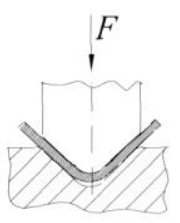

b)

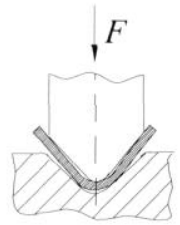

c)

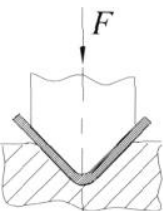

d)
Figure 2. Coin-bending in V-profile a) first stage; b) second stage; c) third stage; d) fourth stage [14]

\section{Experimental setup}

\subsection{Equipment}

The experiment is conducted using a micro-V-bending tool which is mounted on a micro-forming machine $5 \mathrm{kN}$. The dimension of the specimen to be bent is $0.1 \times 1 \times 7.4$ $\mathrm{mm}$ which has obtained from the previous blanking process. Bending angle measurement was carried on with Dyno-Lite digital microscope PRO2 AD-4113ZT. Figure 3 shows the experimental setup of the micro-V-bending.

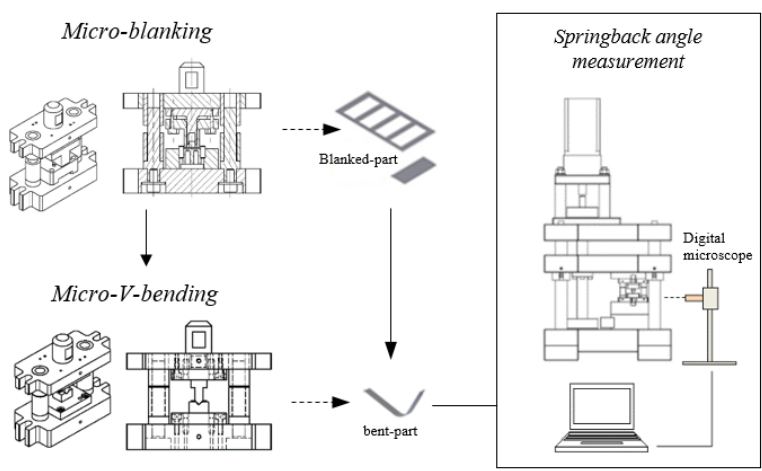

Figure 3. Experimental setup of micro-V-bending process

A die-set of the micro- $\mathrm{V}$-bending tool is prepared to conduct the forming process. The punch and die are Vshaped with certain dimensions. Figure 4 shows a micro$\mathrm{V}$-bending tool with detailed $\mathrm{V}$-shaped in the die. A partially caging system is used to locate the specimen to be bent.

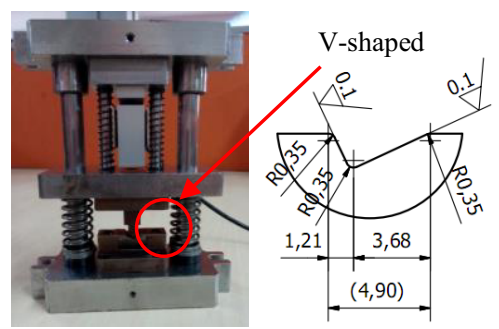

Figure 4. Micro V-bending tool

For the main component, i.e. punch, die and locator, the minimum requirements of material properties can be fulfilled by tool steel material, while the others can use machinery steel. The mechanical properties of the usedmaterial in micro-V-bending tool components can be seen in Table 2 below. For groups of tool steel, it used AISI D2, while AISI 1045 for the machinery steel.

Table 1. Mechanical properties of AISI D2 and AISI 1045

\begin{tabular}{llcc}
\cline { 3 - 4 } & & $\begin{array}{c}\text { Cold Work } \\
\text { ToolSteel } \\
(\mathrm{D} 2 / \text { SKD11) }\end{array}$ & $\begin{array}{c}\text { Machinery } \\
\text { Steel } \\
(1045 / \mathrm{S} 45 \mathrm{C})\end{array}$ \\
\hline $\begin{array}{l}\text { Ultimate } \\
\text { tensile strength }\end{array}$ & {$[\mathrm{MPa}]$} & & 569 \\
\hline Yield Strength & {$[\mathrm{MPa}]$} & 1650 & 343 \\
\hline Elongation & {$[\%]$} & & 20 \\
\hline $\begin{array}{l}\text { Modulus of } \\
\text { Elasticity }\end{array}$ & {$[\mathrm{GPa}]$} & 209.9 & 205 \\
\hline Poissons Ratio & & & 0.29 \\
\hline Machinability & {$[\%]$} & & 55 \\
\hline Shear Modulus & {$[\mathrm{GPa}]$} & & 80 \\
\hline
\end{tabular}


The $\mu$-machine with $5 \mathrm{kN}$ capacity was driven by an Oriental servo motor NX940MS-PS10-3. The mechanical force is transferred to the ram using ball screw and change rotational motion into translational one [15]. The assembled micro forming machine is shown in Figure 5, and Table 2 illustrates the specification of it.
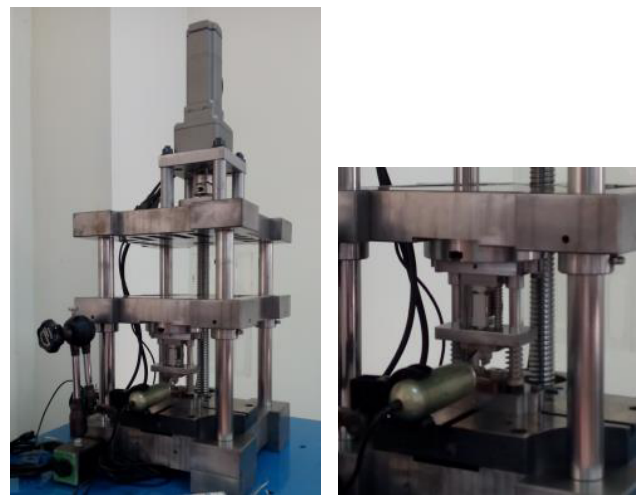

Figure 5. Micro V-bending tool

Table 2. $\mu$-Forming machine $5 \mathrm{kN}$ specification

\begin{tabular}{|c|c|c|}
\hline Maximum Load Capacity & {$[\mathrm{kN}]$} & 5 \\
\hline \multicolumn{3}{|c|}{ Servo motor: NX940MS-PS10-3 } \\
\hline Max holding torque & {$[\mathrm{Nm}]$} & 34.3 \\
\hline $\begin{array}{l}\text { Moment of rotor } \\
\text { inertia }\end{array}$ & {$\left[\mathrm{kg} \cdot \mathrm{m}^{2}\right]$} & $0,314 \cdot 10^{-4}$ \\
\hline Resolution & {$[\mathrm{P} / \mathrm{R}]$} & $\left.100-100000^{*}\right)$ \\
\hline Gear ratio & & 10 \\
\hline Allowable speed range & {$[\mathrm{rpm}]$} & 0 to 300 \\
\hline Backlash & {$\left[{ }^{\circ}\right]$} & 0.25 \\
\hline Resolution & {$[\mu \mathrm{m}]$} & 0.5 to 500 \\
\hline Working area & {$[\mathrm{mm}]$} & $\begin{array}{l}\left.\mathrm{L} \times \mathrm{x} \times \mathrm{h}^{* *}\right) \\
100 \times 200 \times 120\end{array}$ \\
\hline $\begin{array}{l}\text { Average deviation linear } \\
\text { motion }\end{array}$ & {$[\mu \mathrm{m}]$} & $0.5 \div 4$ \\
\hline
\end{tabular}

Copper foil with $0.1 \mathrm{~mm}$ thickness is chosen as a specimen to investigate the micro- $\mathrm{V}$-bending process. Table 3 and 4 show the chemical composition and mechanical properties of the copper foil, respectively. The chemical composition was obtained from Optical Emission Spectrometer, and the tensile test was held on Servopulser Shimadzu 20T. Because the experiment observes with the given properties, no pre-heated process conducted to the material foil.

Table 3. Chemical composition of the copper foil

\begin{tabular}{llllllll}
\hline $\mathrm{Cu}$ & $\mathrm{Zn}$ & $\mathrm{Pb}$ & $\mathrm{Sn}$ & $\mathrm{P}$ & $\mathrm{Mn}$ & $\mathrm{Fe}$ & $\mathrm{Ni}$ \\
$(\%)$ & $(\%)$ & $(\%)$ & $(\%)$ & $(\%)$ & $\begin{array}{l}(\%) \\
(\%)\end{array}$ & $(\%)$ \\
98.5 & 0.191 & 0.024 & 0.046 & 0.195 & 0.003 & $<0.005$ & 0.111 \\
\hline $\mathrm{Si}$ & $\mathrm{Mg}$ & $\mathrm{Cr}$ & $\mathrm{Al}$ & $\mathrm{Ag}$ & $\mathrm{Co}$ & $\mathrm{Bi}$ & $\mathrm{Sb}$ \\
$(\%)$ & $(\%)$ & $(\%)$ & $(\%)$ & $(\%)$ & $(\%)$ & $(\%)$ & $(\%)$ \\
0.042 & 0.001 & 0.003 & 0.009 & 0.006 & 0.044 & 0.213 & 0.027 \\
\hline
\end{tabular}

Table 4. Mechanical properties of copper foil

\begin{tabular}{lll}
\hline Tensile Strength & {$[\mathrm{MPa}]$} & 647 \\
\hline Yield Strength & {$[\mathrm{MPa}]$} & - \\
\hline Elongation & {$[\%]$} & 1.9 \\
\hline
\end{tabular}

\subsection{Experimental process parameters}

The blank part is then bent in the micro V-bending tool to obtain a specified bending angle. One piece loading was also implemented in the bending process. The coinbending method was held, due to the holding time variation was observed in decreasing springback angle. The experiment was conducted with five specimens for each variation of punch speed. i.e. $0.5 \mathrm{~mm} / \mathrm{s} 1 \mathrm{~mm} / \mathrm{s}$, and $5 \mathrm{~mm} / \mathrm{s}$.

Since the micro-tool construction used the wire spring, the punch need time to be unloaded, i.e. $h t_{0}=7$ seconds. Thus, in this research, the holding time is set as shown in Table 5.

Table 5. Mechanical properties of copper foil

\begin{tabular}{|c|c|c|c|}
\cline { 2 - 4 } \multicolumn{1}{c|}{} & \multicolumn{3}{c|}{ Holding time set } \\
\cline { 2 - 4 } \multicolumn{1}{c|}{} & 1 & 2 & 3 \\
\hline \multirow{2}{*}{ Time [s] } & $\mathrm{ht}_{0}+0$ & $\mathrm{ht}_{0}+2$ & $\mathrm{ht}_{0}+4$ \\
\cline { 2 - 4 } & 7 & 9 & 11 \\
\hline
\end{tabular}

Bending angle measurement was carried on with digital microscope Dyno-Lite PRO2 AD-4113ZT, as soon as the bending part was unloaded. Figure 6 shows (a) bottoming position and (b) the measurement of bending angle.

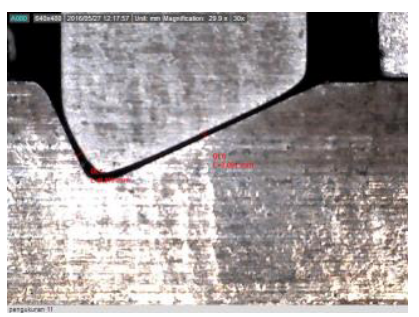

(a)

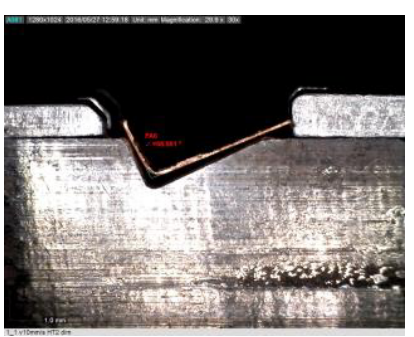

(b)

Figure 6. (a). Bottoming position (b) bending angle measurement

\section{Result and discussion}

In the micro V-bending experiment, the measured springback showed difference relating to the punch velocity and holding time variation. Figure 7 to 9 describe the occurring springback for each parameter variation. Good tendencies are showed with the $0.5 \mathrm{~mm} / \mathrm{s}$ and $1 \mathrm{~mm} / \mathrm{s}$ punch velocity (Figure 7 and 8 ). The inconsistent result is produced with $10 \mathrm{~mm} / \mathrm{s}$ punch velocity. The springback angle increased in $2^{\text {nd }}$ holding time set and then decreased slightly with a longer holding time (Figure 9). 


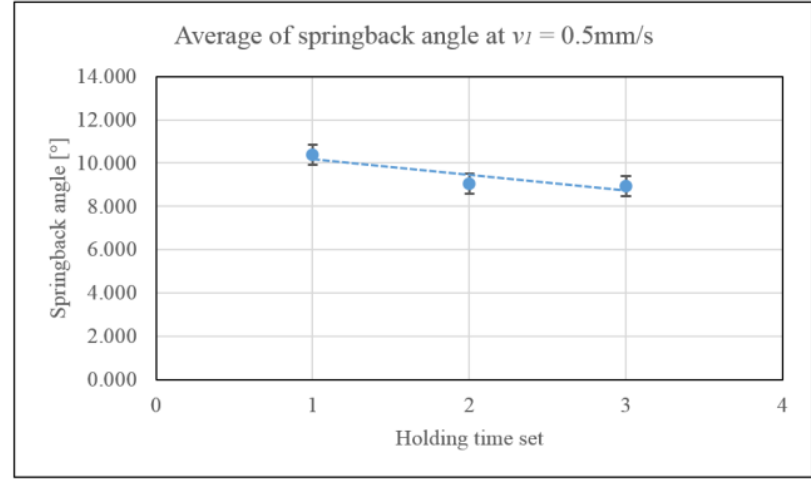

Figure 7. Average of springback angle at $v_{l}=0.5 \mathrm{~mm} / \mathrm{s}$

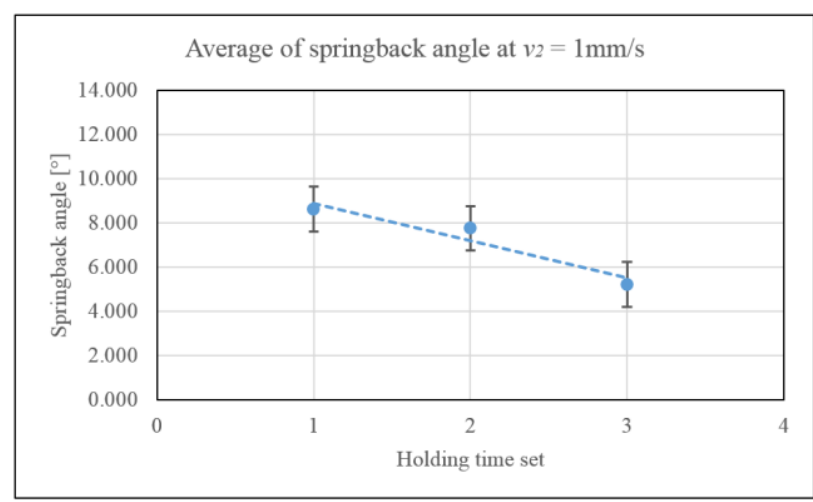

Figure 8. Average of springback angle at $v_{2}=1 \mathrm{~mm} / \mathrm{s}$

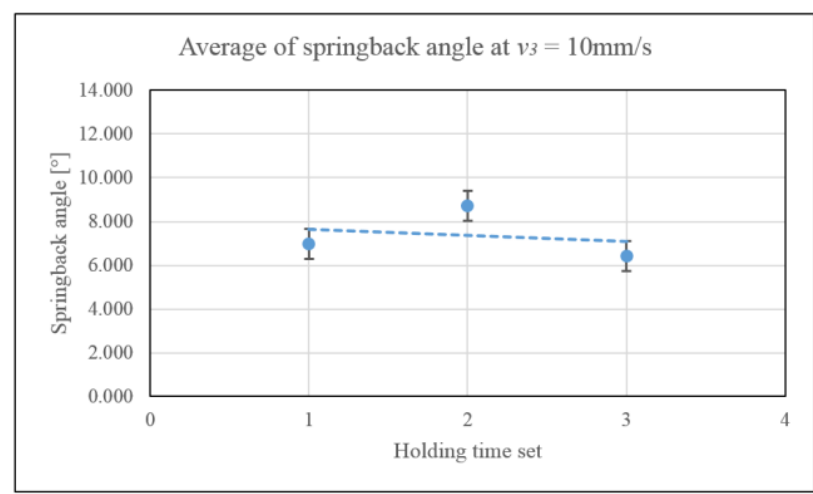

Figure 9. Average of springback angle at $v_{3}=10 \mathrm{~mm} / \mathrm{s}$

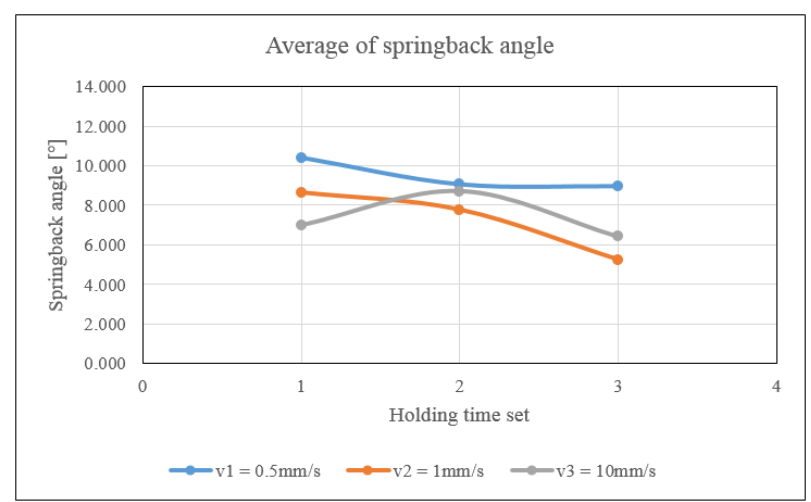

Figure 10. Average of springback angle

Figure 10 shows the average of springback angle for punch speed and holding time set variation. It can be seen obviously that the springback angle can be reduced by applying a higher punch velocity. With an appropriate holding time, the springback angle will be more reducible.

\section{Conclusions}

The results show that the determined process parameters can improve the product quality in the micro process. The springback angle indicates the differences when punch velocity variation was observed. The springback angle decreases with the higher punch velocity. Also, the variation of holding time during bottoming stage has a potential to reduce springback angle.

For future works, it needs more investigation of the holding time regarding decrease the springback angle. Another material should be observed to find out the characteristic of springback reduction with a variation of determined process parameters.

\section{References}

1. Qin, Y., Micro-forming and miniature manufacturing systems - development needs and perspectives. Journal of Materials Processing Technology, 177(1-3): p. 8-18 (2006)

2. Gau, J.-T., C. Principe, and M. Yu, Springback behavior of brass in micro sheet forming. Journal of Materials Processing Technology, 191(1-3): p. 7-10, (2007)

3. Diehl, A., U. Engel, and M. Geiger, Influence of microstructure on the mechanical properties and the forming behaviour of very thin metal foils. The International Journal of Advanced Manufacturing Technology, 47(1-4): p. 53-61 (2010)

4. Liu, J., et al., Influence of size effect on the springback of sheet metal foils in micro-bending. Computational Materials Science, 50(9): p. 26042614 (2011)

5. Ma, Z., et al., Grain size effect on springback behavior in bending of Ti-2.5Al-1.5Mn foils. Journal of Materials Processing Technology, 224: p. 11-17. (2015)

6. Chen, C.-C., and C.-P. Jiang, Grain Size Effect in the Micro-V-Bending Process of Thin Metal Sheets. Materials and Manufacturing Processes, 26(1): p. 7883 (2011)

7. Zhu, H.X. and B.L. Karihaloo, Size-dependent bending of thin metallic films. International Journal of Plasticity, 24(6): p. 991-1007 (2008)

8. Hezong, L., et al., Determination of material intrinsic length and strain gradient hardening in microbending process. International Journal of Solids and Structures, 48(1): p. 163-174 (2011)

9. AHMET PARASIZ, S., R. VanBenthysen, and B.L. Kinsey, Deformation size effects due to specimen and grain size in microbending. Journal of manufacturing science and engineering, 132(1) (2010)

10. Li, H.-z., et al., Analysis of microbending of CuZn37 brass foils based on strain gradient hardening models. Journal of Materials Processing Technology, 212(3): p. 653-661 (2012)

11. Fang, Z., et al., Study on springback in micro $V$ bending with consideration of grain heterogeneity. The International Journal of Advanced 
Manufacturing Technology, 78(5-8): p. 1075-1085 (2015)

12. Huang, Z.-y., H. Zhang, and F. Ruan, Control Method of the Spring Back in Bending Micro and Precise Stamping Parts, in Proceedings of the 2009 International Conference on Measuring Technology and Mechatronics Automation - Volume 012009, IEEE Computer Society. p. 782-784.

13. Zheng, Q., T. Shimizu, and M. Yang, Scale effect on springback behavior of pure titanium foils in microbending at elevated temperature. Journal of
Materials Processing Technology, 230: p. 233-243, (2016)

14. Boljanovic, V., Sheet Metal Forming Process and Die Design. New York: Industrial Press Inc. 184. (2004)

15. Kiswanto, G., A. Mahmudah, and S. Supriadi. Development and Testing of $5 \mathrm{kN}$ Micro Forming Machine for Micro Part Manufacturing. in 13th Quality in Research. Yogyakarta, Indonesia, (2013) 